\title{
UM ZOOLÓGICO DE SIGNIFICADOS: A FUNÇÃO DOS ANIMAIS EM ALGUNS TEXTOS DE MACHADO DE ASSIS
}

Eduardo Viana da Silva

Universidade da Califórnia

Santa Barbara (CA), Estados Unidos

\begin{abstract}
Resumo: Este artigo apresenta o uso de animais como símbolos e metáforas em alguns textos de Machado de Assis, com ênfase nos romances Quincas Borba e Memórias póstumas de Brás Cubas, além de no conto "A Sereníssima República". Procura-se articular como Machado de Assis utiliza a figura dos animais na construção de sua narrativa, inserindo-a no contexto da literatura universal, no que diz respeito à imagem dos animais.
\end{abstract}

Palavras-chave: símbolos; metáforas; animais.

\section{A zoological of meanings: the function of animals in some texts by Machado de Assis}

\begin{abstract}
This article presents the use of animals as symbols and metaphors in some texts by Machado de Assis. It focuses on two novels, Quincas Borba and Memórias póstumas de Brás Cubas, and on the short-story "A Sereníssima República". It aims to analyse how Machado de Assis uses the figure of animals in the construction of his narrative, in the context of world literature regarding animal imagery.
\end{abstract}

Keywords: symbols; metaphors; animals.

O simbolismo dos animais na literatura tem sido explorado desde a Antiguidade grega, como se constata nos poemas épicos de Homero, Ilíada e Odisseia. A utilização de animais como símbolo e metáfora constitui-se em um elemento literário importante na literatura universal e o mesmo ocorre na obra de Machado de Assis. Os animais pertencentes à obra machadiana não aparecem como simples elementos de 
adorno. Ao contrário, cada animal utilizado por Machado de Assis possui uma função exclusiva no enredo de seus romances e contos. De acordo com esta perspectiva, a apresentação de animais, como uma borboleta em Memórias póstumas de Brás Cubas ${ }^{1} \mathrm{e}$ um cachorro em Quincas Borba, ${ }^{2}$ segue também a premissa de atender a uma função nas respectivas narrativas. Este artigo tem como objetivo delinear certas funções de alguns animais em dois romances e em um conto machadiano. Este estudo se centraliza na representação dos seguintes animais utilizados por Machado de Assis: o cachorro em QB; o verme, o hipopótamo e a borboleta em MPBC; e a aranha no conto "A Sereníssima República"; além de analisar algumas metáforas com animais utilizadas pelo autor como uma técnica narrativa.

O primeiro animal apresentado extensamente por Machado é o cachorro Quincas Borba. Quincas recebeu o nome de seu dono e, "coincidentemente", é também o título do livro: Quincas Borba. O cachorro Quincas é descrito como um ser humano, com a atribuição de sentimentos e atitudes concernentes aos humanos. Nota-se na descrição que se segue a escolha de adjetivos que humanizam o cachorro: "Quincas Borba apareceu. Magro, abatido, parou à porta da sala, estranho às duas senhoras, mas sem latir; mal erguia os olhos apagados". ${ }^{3}$ Se não fosse pelo verbo latir, seria possível atribuir a descrição acima a uma pessoa; especialmente, o adjetivo "abatido" dá-nos a noção de que se trata de um ser humano, e não de um animal de estimação. Essa caracterização humanizada do cachorro é uma constante dentro da narrativa e é justificada pelo fenômeno da transmigração de almas e pelos delírios.

Já desde criança Rubião acreditava na possibilidade da transmigração de almas, dado o seu contato com uma preta de São João d'El-Rei, a qual the explicou que as almas cheias de pecado transmigravam para o corpo de um bruto: "chegou a jurar que conhecera um escrivão que acabou feito gambá...". ${ }^{4}$ Logo após a morte de seu amigo Quincas Borba, Rubião dá-se conta da possibilidade de o cachorro carregar em si a alma de seu amigo. O comentário de um cocheiro desperta a ideia da transmigração de almas

\footnotetext{
${ }^{1}$ De agora em diante utilizarei MPBC.

${ }^{2}$ De agora em diante utilizarei QB.

${ }^{3}$ ASSIS, Machado de. Quincas Borba. Edição do texto e notas: Eugênio Vinci de Moraes. Prefácio: Willi Bolle. São Paulo: Editora Globo S.A., 2008. p. 316.

${ }^{4}$ Idem, p. 110.
} 
em Rubião: "Este cavalo tem-me uma amizade [...] Quem sabe que cavalo e cachorro são os animais que mais gostam da gente? Cachorro parece que ainda gosta mais...". 5 Rubião passa então a imaginar a possibilidade de Quincas Borba ter transmigrado sua alma para o seu cachorro, o que justificaria toda a atenção dada ao cão em seu testamento, no qual Quincas pede que o cachorro seja tratado como uma pessoa: "Exigia do dito Rubião que o tratasse como se fosse a ele próprio testador, [...] cuidar finalmente como se cão não fosse, mas pessoa humana". ${ }^{6}$

$\mathrm{Na}$ literatura universal, o simbolismo do cão apresenta duas funções distintas: ou o cão representa o insulto ou a fidelidade. É notório na literatura clássica o emprego da palavra cachorro como um insulto:

Em Deuteronômio 23: 18, "cão" significa "sodomita". Em Homero, os termos com a palavra "cão" são aplicados principalmente às mulheres ou deusas com a sugestão distinta de promiscuidade. Em Ilíada, Helena chama a si mesma de "um cão horrível [ou cadela]" (6.344). Zeus diz a Hera "não há nada mais canino do que sua presença".

A lista de insultos utilizando a palavra "cachorro" se estende, na literatura, de obras como a Ilíada às peças de Shakespeare. No entanto, o cão é também associado à fidelidade, e o nome Fido, o italiano para "fiel", é ainda hoje dado a cães. O primeiro cachorro apresentado na literatura do Ocidente, de acordo com Ferber, é o cão Argos, na Odisseia. É Argos quem encontra Odisseu, em uma cena memorável da obra:

Lá, o cão Argos deita-se no esterco, todo coberto de carrapatos. Agora, como ele percebeu que Ulisses [disfarçado] havia chegado perto dele, abanou o rabo e dobrou ambas as orelhas para trás, mas a

\footnotetext{
${ }^{5}$ Idem, p. 110.

${ }^{6}$ Idem, p. 65.

7 Tradução minha para: "In Deuteronomy 23.18 'dog' means 'sodomite'. In Homer dog-terms are applied mainly to women or goddesses with the distinct suggestion of sexual looseness. In the Iliad Helen calls herself 'a horrible dog [or bitch]' (6.344). Zeus tells Hera 'there is nothing more doglike than you."' FERBER, Michael. A dictionary of literary symbols. Nova Iorque: Cambridge University Press, 2007. p. 60 .
} 
destruição da morte negra apoderou-se do cão, Argos, quando, após 19 anos, ele havia visto Odisseu. ${ }^{8}$

Se, de fato, o cão é o melhor amigo do homem, Quincas Borba é um cão duplamente amigo. Não somente o cachorro Quincas acompanhou seu dono em vida, mas também teria recebido a sua alma. Além disso, o cão Quincas Borba foi um dos poucos amigos verdadeiros de Rubião, com exceção do filósofo Quincas Borba, que lhe deixou sua herança, e de D. Fernanda, que teve compaixão por Rubião durante as suas crises mentais. Sendo assim, o cachorro possui na obra a função de ser um dos personagens principais, e é bem possivelmente a ele que o título do romance se refere. A ironia machadiana permeia toda a narrativa, especialmente na interação entre Rubião e o cachorro: "Pobre Quincas Borba! Gosta de seu senhor, não gosta? Rubião é muito amigo de Quincas Borba!". 9 De fato, a amizade de Rubião pelo cachorro aumenta à medida que a narrativa progride e a ideia da transmigração de almas passa a consolidarse na cabeça de Rubião:

Quincas Borba, que estava com ele no gabinete, deitado, levantou casualmente a cabeça e fitou-o. Rubião estremeceu; a suposição de que naquele Quincas Borba podia estar a alma do outro nunca se lhe varreu inteiramente do cérebro. ${ }^{10}$

Ao final do romance, Rubião e Quincas são amigos inseparáveis. Parece que Rubião acaba se convencendo por completo de que o cachorro é na verdade o seu falecido amigo e por esta razão o leva consigo para onde quer que vá.

No estilo irônico-satírico de Machado, o cão Quincas representa o homem e o cachorro e, de certa maneira, atua como uma resposta à filosofia do Humanitismo criada por Quincas Borba, na qual o ser humano não é superior ao animal; o que importa é a espécie, e não o indivíduo. Essa inversão na ordem de valores é também refletida no

\footnotetext{
${ }^{8}$ Tradução minha para: "There the dog Argos lay in the dung, all covered with dog ticks. Now, as he perceived that Odysseus [in disguise] had come close to him, he wagged his tail, and laid both his ears back; But the doom of dark death now closed over the dog, Argos, when, after nineteen years had gone by, he had seen Odysseus." Idem, p. 60.

${ }^{9}$ ASSIS. Machado de. Quincas Borba, cit., p. 316.

${ }^{10}$ Idem, p. 148-149.
} 
texto, no qual o cachorro acaba por aparecer em mais cenas do que o seu dono Quincas. Ao final do livro, durante a interação entre D. Fernanda e Quincas Borba, o narrador cria um momento de conexão profunda entre ambos os personagens: "Quando Dona Fernanda cessou de acariciá-lo e levantou o corpo, ele ficou a olhar para ela, e ela para ele, tão fixos e tão profundos, que pareciam penetrar no íntimo um do outro". ${ }^{11}$ Neste momento intenso, o narrador indica que D. Fernanda e Quincas atuam "como se ambos representassem a mesma espécie". ${ }^{12}$ Certamente, nota-se a interferência do narrador, reforçando dois aspectos da narrativa: a transmigração de almas e a teoria do Humanitismo; e, sendo assim, causando uma ruptura com os ensinamentos bíblicos, dos quais não faz parte a doutrina da transmigração das almas.

Além da transmigração, outra possibilidade é a de que o cachorro tenha sido visto como um ser humano na ótica de dois homens mentalmente desequilibrados: Quincas Borba e Rubião. O delírio é um dos eixos ao redor do qual gira essa obra. A humanização do cachorro Quincas pode ser fruto dos delírios de Quincas Borba e de Rubião, além das interferências do autor, que em determinados momentos confundem o leitor, por alternarem as descrições do cachorro entre as opiniões dos personagens e a narração em si. No capítulo IX, o narrador faz a seguinte descrição do cão, que se encontra desolado na ausência de seu dono: "Mais tarde, passava as horas calado, triste, enrolado em si mesmo, ou então com o corpo estendido e a cabeça entre as mãos". ${ }^{13}$ Ora, a técnica narrativa machadiana induz o leitor a enxergar um cão que possui mãos em vez de patas e que fica triste e introspectivo. O próprio Rubião menciona que o cão "parece gente". ${ }^{14}$ Sendo assim, a arapuca está armada, e o leitor pode deixar-se levar pela narração de um cachorro com características humanas e escolher entre o delírio de Quincas e Rubião ou a transmigração de almas.

Em MPBC, há três animais que desempenham funções diferentes na narrativa: um verme, um hipopótamo e uma borboleta. O narrador Brás Cubas dedica suas memórias ao verme que roeu suas carnes: "Ao verme que primeiro roeu as frias carnes

\footnotetext{
${ }^{11}$ Idem, p. 317.

${ }^{12}$ Idem, p. 317.

${ }^{13}$ Idem, p. 59.

${ }^{14}$ Idem, p. 59.
} 
do meu cadáver dedico como saudosa lembrança estas memórias póstumas". ${ }^{15} \mathrm{~A}$ dedicatória ao verme no início do romance enfatiza o sarcasmo presente na narrativa, já que, entre todas as pessoas que passaram pela vida de Brás Cubas, ninguém foi merecedor de receber a dedicatória de suas memórias. Dos onze amigos que acompanharam o funeral, somente um se pronunciou em um discurso muito emotivo e poético (incentivado pelo clima chuvoso), e este é justamente o que participou da herança de Brás: "Bom e fiel amigo! Não, não me arrependo das vinte apólices que lhe deixei". ${ }^{16}$ Nota-se que Brás escolhe talvez o animal mais ínfimo para sua dedicatória, que, no entanto, foi o que teve o "trabalho" de cuidar de seu corpo, de processá-lo e de integrá-lo à terra: o verme. Seria, talvez, o mesmo que dizer que dentre todos os seres, o que mais lhe valeu após a sua morte foi o verme, e não os seres humanos; o verme assume a função daquele que é prestigiado. Cabe aqui ressaltar que o verme é um símbolo utilizado na literatura desde a Bíblia. É constante a sua associação com a morte, processo no qual os corpos humanos servem de comida aos vermes. Assim como Brás prestigia o verme em sua dedicatória, algo similar faz Byron ao comparar os vermes a deuses:

Para Sardanapalus, de Byron, a noção de que alguns homens são deuses é descartada: "os vermes são deuses;/ Pelo menos, eles banqueteavam os seus deuses,/ E morriam por falta de mais nutrientes" (1.2.269-71). Como a morte é o grande nivelador, os vermes são revolucionários; Byron diz que todo monarca é chamado de Sua Alteza "até que sejam consignados/ àqueles jacobinos tristes com fome, os vermes, / por quem os reis mais poderosos foram jantados". ${ }^{17}$

De certa maneira, Machado de Assis utiliza a figura do verme dentro de uma tradição literária, na qual a sua associação à morte pode também ser exaltada por ser o

\footnotetext{
${ }^{15}$ ASSIS, Machado de. Memórias póstumas de Brás Cubas. Obras Completas de Machado de Assis. v. 5. Org. Ary de Mesquita. São Paulo: W. M. Jackson, 1957. p. 5.

${ }^{16}$ Idem, p. 11.

17 Tradução minha para: "Byron's Sardanapalus dismisses the notion that some men are gods: 'the worms are gods; /At least they banqueted upon your gods, / And died for lack of further nutriment' (1.2.269-71). As death is the great leveler, worms are revolutionaries; Byron says every monarch is called Your Highness 'till they are consigned/ To those sad hungry Jacobins the worms, / Who on the every loftiest kings have dined."' FERBER, Michael. A Dictionary of Literary Symbols, cit., p. 243.
} 
verme quem realiza o "banquete final", assim como Byron sugere através de seu personagem Sardanapalus, o último rei da Assíria.

A partir da dedicatória ao verme em MPBC, o narrador já estabelece o tom de sua narrativa, a qual encontrará no sarcasmo uma técnica de escrita presente no decorrer da obra. Não é de se estranhar que Machado se utilize de sátira em MPBC. O autor brasileiro era leitor do francês e inglês e extremo admirador dos autores Swift ${ }^{18}$ e Sterne. A sátira de Sterne, assim como a de Machado, encontra-se nas entrelinhas do texto.

A presença do hipopótamo também contém elementos da sátira e da ironia em MPBC. No capítulo VII, intitulado "O delírio", Brás narra como um hipopótamo lhe serve de guia e o leva em uma viagem histórica para demonstrar a origem dos séculos. O hipopótamo assume a função de líder do delírio de Brás, um animal falante que o leva em uma viagem através dos tempos, passando pelo Jardim do Éden e colocando-o frente a frente com a Natureza (Pandora). Na literatura universal, o hipopótamo simboliza a brutalidade, a destruição e também a fecundidade. O Livro de Jó descreve Behemoth como "uma criatura voraz no formato de um hipopótamo, simbolizando as necessidades humanas pela ajuda divina para conquistar sua brutalidade". ${ }^{19}$ Nessa passagem bíblica, Deus fala a Jó sobre a criação do mundo e introduz a figura de Behemoth, um monstro valente que simboliza o poder absoluto, com o objetivo de demonstrar a Jó que a sua função na terra é como a de outros seres:

Behemoth é o nome dado a uma criatura que aparece em Jó 40: 1524. Ele é, segundo o texto, a maravilha maior de Deus na terra, e seu duplo, o Leviatã, seria a grande criatura do mar. Descrito como um animal gigante, herbívoro e de corpo couraçado, o Behemoth teria "à sombreira do lótus, entre o junco do pântano e debaixo do salgueiro" como sua morada. Do hebraico, a palavra "behemoth" seria o equivalente a "hipopótamo", "elefante" ou "besta". Em um diálogo entre Jó e o Criador, esse monstro é apresentado por Deus como uma

\footnotetext{
${ }^{18}$ Swift propôs sarcasticamente que as crianças irlandesas que representavam um gasto oneroso ao reino inglês fossem assadas e comidas, pois assim seriam mais úteis à sociedade da época (século XVIII).

19 Tradução minha para: "a voracious hippopotamus-like creature, symbolizing humanity needs for the divine help to conquer its brutishness." TRESIDDER, Jack. The complete dictionary of symbols. São Francisco: Chronicle Books, 2005. p. 238.
} 
potência, a fim de se diminuir a soberba da personagem diante dos feitos divinos. ${ }^{20}$

É através desse animal grandioso e feroz, o hipopótamo, que Brás Cubas conhece a Natureza: "- Chama-me Natureza ou Pandora; sou tua mãe e tua inimiga". ${ }^{21}$ A Natureza se refere a Brás como um verme: "- Sim, verme, tu vives". ${ }^{22}$ Retornamos aqui à referência de verme como um ser inferior: "Na Bíblia, o verme é considerado a criatura de mais baixo nível, o mais distante possível da figura de Deus. Comparado com Deus, no entanto, o homem é também um verme". ${ }^{23}$ A Natureza está determinada a demonstrar a Brás sua insignificância como um ser mortal, assim como os outros animais. Nesse suposto delírio, o narrador, ironicamente, abre os olhos do leitor para a fragilidade da vida humana e a relativa importância da mesma. A narração do delírio enfatiza que os seres humanos fazem parte de um universo de seres, assim como os animais, e que seguem o ciclo da vida, nascem, lutam pela sobrevivência e morrem, sem que um valha mais do que o outro. Ao pedir por mais alguns minutos de vida, a Natureza responde com muita ironia ao pedido de Brás: "Para que queres tu mais alguns instantes de vida! Para devorar e seres devorado depois! Não estás farto do espetáculo e da luta?". ${ }^{24}$ A luta pode ser vista como a lei do mais forte da teoria spenceriana. Nessa luta pela sobrevivência, a Natureza apresenta um exemplo do mundo animal para Brás, justificando assim a morte de um animal para manter a sobrevivência de outro: "A onça mata o novilho porque o raciocínio da onça é que ela deve viver, e se o novilho é tenro tanto melhor: eis o estatuto universal. Sobe e olha". ${ }^{25}$ Sendo assim, através do delírio, Brás toma consciência de sua função como ser humano, seguindo a filosofia da Natureza, na qual morte e vida são "espetáculos" necessários e indispensáveis. Não

${ }^{20}$ FARIA, Marcos. Behemoth, Lilith e Anjos: três monstros judaicos em Jorge Luis Borges. Arquivo Maaravi: revista digital de estudos judaicos da UFMG, Belo Horizonte: v.3, n.5, out. 2009. Disponível em: <www.periodicos.letras.ufmg.br/index.php/maaravi>. Acesso em: 2 fev. 2012.

${ }^{21}$ ASSIS, Machado de. Memórias póstumas de Brás Cubas, cit., p. 32.

${ }^{22}$ Idem, p. 33.

${ }^{23}$ Tradução minha para: "From the Bible onward the worm is the lowest of creatures, as far removed as possible from God. Compared to God, however, man is also a worm". FERBER, Michael. A dictionary of literary symbols, cit., p. 241.

${ }^{24}$ ASSIS, Machado de. Memórias póstumas de Brás Cubas, cit., p. 34.

${ }^{25}$ Idem, p. 35. 
existe uma razão lógica para prolongar a vida do ser humano que não seja baseada no egoísmo, já que toda a vida dos seres é "naturalmente" submetida à lei do mais forte. Logo, é desnecessário pedir por mais tempo de vida; não há consolo na religião e a morte é inevitável. O hipopótamo tem como função demonstrar a Brás a tragédia da vida humana e a verdade da natureza: o indivíduo traz consigo o desejo de viver, mas a morte é inevitável.

Além do verme e do hipopótamo, a borboleta assume também uma função importante na narrativa de MPBC. Nos capítulo XXX e XXXI, temos a aparição de uma borboleta preta. No mundo das superstições, a borboleta preta é um símbolo da morte. No capítulo XXX, a personagem D. Eusébia apavora-se ao ver uma borboleta negra que entra na varanda de sua casa: "Dona Eusébia deu um grito, levantou-se, praguejou umas palavras soltas: - T'esconjuro!... sai, diabo!... Virgem Nossa Senhora!...". ${ }^{26}$ Neste instante, Brás Cubas apanha a borboleta preta com um lenço, assinalando assim a presença da morte. Considerando que o livro é um diário póstumo e que Brás é um defunto que narra a sua própria vida, a aparição de uma borboleta negra não é fortuita.

O capítulo XXXI de MPBC tem como título "A borboleta preta". Brás vê-se novamente frente a frente com outra borboleta preta, desta vez maior e que, na visão do narrador, "tinha um certo ar escarninho, uma espécie de ironia mefistofélica". Percebese aqui a comparação reiterada do indivíduo versus a espécie. A borboleta representa a morte e a espécie; Brás, por sua vez, representa o indivíduo; e tudo nos leva a crer que a teoria do Humanitismo de Quincas Borba põe-se em ação. Ao matar a borboleta, Brás possivelmente mata a ideia da morte a lhe rondar, mas, de acordo com o Humanitismo de Quincas, a ordem natural dos acontecimentos da natureza é implacável e não se altera pela ação do homem. De acordo com Daniel Piza, o Humanitismo é uma filosofia que se adapta a todas as filosofias: "Mescla elementos do darwinismo social, ao pregar a lei dos mais fortes, com o conceito de 'mônada' de Leibniz [...] que diz que uma mesma substância espiritual habita todos os seres". ${ }^{27}$ A ação de Brás Cubas, matar a borboleta, não pode impedir sua própria morte. Brás põe-se a observar a borboleta em um momento de contemplação: "Deixei-me estar a contemplar o cadáver, com alguma

\footnotetext{
${ }^{26}$ Idem, p. 118.

${ }^{27}$ PIZA, Daniel. Machado de Assis: um gênio brasileiro. São Paulo: Imprensa Oficial, 2008. p. 208.
} 
simpatia, confesso". ${ }^{28}$ É possível criar uma ponte entre Brás e a borboleta, na qual Brás representa o indivíduo, o homem, gigante da natureza, e a borboleta representa a pequenez, o ser ínfimo que pode ser facilmente morto pelo gigante, assim como no romance de Jonathan Swift (1667-1745) Viagens de Gulliver, no qual o autor faz uma sátira do tamanho, onde Gulliver é o gigante na terra dos pequeninos. Da mesma maneira, Brás é o gigante aos olhos da borboleta, como assim é descrito: "e viu que me movia, que tinha olhos, braços, pernas, um ar divino, uma estatura colossal. Então disse consigo: 'Este é provavelmente o inventor das borboletas'". ${ }^{29}$ Ao pensar nisto, a borboleta lhe "beija" a testa e vê o retrato do pai de Brás. Notemos que Brás assume agora a posição do criador e seu pai seria o criador do criador, em uma analogia a Cristo e a Deus. É após essa sequência de acontecimentos que a borboleta é morta por uma toalhada de Brás Cubas. A morte novamente ocupa um espaço de destaque no enredo do livro. Ao mesmo tempo em que Brás se coloca em uma posição de criador, desafiando os preceitos cristãos, ele também enfatiza a efemeridade da vida e o ciclo da natureza: "Era tempo; aí vinham já as próvidas formigas..."; ${ }^{30}$ ou seja, o ciclo da vida segue e agora é a vez das formigas consumirem a borboleta, assim como o verme roeu as carnes frias de Brás Cubas.

No capítulo XXXIII, a imagem da borboleta preta retorna à narrativa. Desta vez, Brás faz referência a Eugênia, filha de D. Eusébia. Brás havia descoberto que Eugênia era coxa e, à noite, após a visita à casa de D. Eusébia, ele pondera sobre a desfortuna de Eugênia: "Uns olhos tão lúcidos, uma boca tão fresca, uma compostura tão senhoril; e coxa!". ${ }^{31}$ Existe possivelmente uma relação entre esse capítulo e o capítulo da borboleta preta. Brás chega à conclusão de que: "Esse contraste faria suspeitar que a natureza é às vezes um imenso escárnio". ${ }^{32}$ Essa impressão é a mesma que o narrador apresentou anteriormente, ao observar a borboleta preta, no capítulo XXXI: "Era negra como a noite, e o gesto brando com que, uma vez posta, começou a

\footnotetext{
${ }^{28}$ ASSIS, Machado de. Memórias póstumas de Brás Cubas, cit., p. 121.

${ }^{29}$ Idem, p. 121.

${ }^{30}$ Idem, p. 122.

${ }^{31}$ Idem, p. 126.

${ }^{32}$ Ibidem.
} 
mover as asa, tinha um certo ar escarninho, que me aborreceu muito". ${ }^{33}$ Ao pensar em Eugênia, linda e coxa, e relacioná-la ao escárnio da natureza, Brás decide fazer com Eugênia o mesmo que fez com a borboleta preta - livrar-se dela, livrar-se do pensamento que o incomodava:

Por que bonita, se coxa? Por que coxa, se bonita? [...] O melhor que há, quando se não resolve um enigma, é sacudi-lo pela janela fora; foi o que eu fiz; lancei mão de uma toalha e enxotei essa outra borboleta preta, que me adejava no cérebro. ${ }^{34}$

A alusão à borboleta preta e a Eugênia é clara: ambas representam um defeito da natureza. Brás resolve então tirar Eugênia de seu pensamento e, desta maneira, manter o seu status social, que o impediria de se casar ou namorar uma mulher coxa.

O último animal aqui analisado é a aranha, no conto "A Sereníssima República". Nesse conto, as aranhas possuem um papel central, representando, inicialmente, o trabalho, a organização e a dedicação. $O$ conto, narrado em primeira pessoa, é na realidade um trabalho de pesquisa científica divulgado em uma conferência sobre a importância das aranhas. No estudo dos símbolos, as aranhas possuem primordialmente três características: "(i) o poder criativo das aranhas, como no exemplo da composição de suas teias, (ii) a agressividade das aranhas, e (iii) a teia da aranha como uma rede espiral que converge para um ponto central". ${ }^{35}$ No conto de Machado, as aranhas comunicam-se entre si e se organizam, formando uma sociedade democrática, uma república. $\mathrm{O}$ narrador enaltece $\mathrm{o}$ valor das aranhas quando comparadas a outros animais. As aranhas são animais que trabalham em silêncio; não roubam de outros, como as formigas; não são dependentes; não sugam o sangue, como as pulgas: "A aranha, senhores, não nos aflige nem defrauda; apanha as moscas, nossas inimigas, fia, tece, trabalha e morre. Que melhor exemplo de paciência, de ordem, de

\footnotetext{
${ }^{33}$ ASSIS, Machado de. Memórias póstumas de Brás Cubas, cit., p. 120.

${ }^{34}$ Idem, p. 126.

${ }^{35}$ Tradução minha para: "(i) the creative power of the spider, as exemplified in the weaving of its web; (ii) the spider's aggressiveness; and (iii) the spider's web as a spiral net converging towards a central point." CIRLOT, Juan Eduardo. A dictionary of symbols [Un diccionário de símbolos actuales]. Jack Sage (trad). Nova Iorque: Dover, 2002. p. 304.
} 
previsão, de respeito e de humanidade " $^{36}$ A ironia reside no fato de que as aranhas descritas nesse conto não conseguem se organizar perfeitamente e parecem ter tendências ao roubo, principalmente durante as eleições. As aranhas acabam por criar leis que não são eficazes e necessitam de emendas e mudanças infindáveis, e mesmo assim não alcançam o seu objetivo. Machado usa da ironia e das aranhas para criticar o sistema republicano. Porém, sabemos que Machado de Assis não possuía uma posição política clara e não escrevia literatura de propaganda. $O$ que sim é evidente é a consciência de Machado de que a Proclamação da República e o sistema de votos não representavam necessariamente uma mudança de poder. Podemos observar seu ceticismo no trecho abaixo, retirado da crônica do jornal A Semana, de 8 de dezembro de 1895:

\begin{abstract}
Mas que remédio dou então para fazer todas as eleições puras? Nenhum; não entendo de política. Sou um homem que, por ler jornais e haver ido em criança a galerias das câmaras, tem visto muita reforma, muito esforço sincero de alcançar a verdade eleitoral, evitando a fraude e a violência, mas por não saber de política, ficou sem saber a causa do malogro de tantas tentativas. [...] Vi outras reformas; vi a eleição direta servir aos dois partidos, conforme a situação deles. Vi... Que não tenho eu visto com estes pobres olhos? ? $^{37}$
\end{abstract}

Concordo com Alfredo Bosi que, apesar do ceticismo de Machado de Assis, não se pode definir claramente qual era sua posição diante das diversas variantes do regime republicano. ${ }^{38} \mathrm{O}$ que fica claro, sim, é que Machado de Assis tinha ciência de que o Brasil era dominado por uma elite que continuava no poder no cenário político do Brasil-República. Em 11 de maio de 1888, Machado encerra sua crônica com uma citação em alemão que parece dizer, em uma língua estrangeira, uma verdade por ele

\footnotetext{
36 ASSIS, Machado de. A Sereníssima República. Obras Completas de Machado de Assis. Papéis Avulsos. v. 12. Org. Ary de Mesquita. São Paulo: W. M. Jackson, 1957. p. 242-243

${ }^{37}$ Citado por BOSI, Alfredo. Brás Cubas em três versões: estudos machadianos. São Paulo: Companhia das Letras, 2006. p. 93-94.

${ }^{38}$ Idem, p. 94.
} 
aceita: "Es dürfte leicht zu erwisen sein, dass Brasilien weniger eine knostitutionelle Monarchie als eine absolute Oligarchie ist" ${ }^{39}$

Retornando ao simbolismo das aranhas e ao seu sistema de votação, nota-se que algumas delas estão provavelmente participando de fraudes durante as eleições. $\mathrm{O}$ sistema de eleições adotado baseava-se naquele utilizado na antiga Veneza, no qual os nomes dos candidatos eram escritos em bolas e colocadas dentro de um saco para serem sorteadas. Em certo momento do conto, algumas das bolas das aranhas tinham erros de escrita e eram eliminadas; em um determinado ponto, um candidato retirou uma bola com o seu próprio nome; e os exemplos se seguem. A idoneidade das aranhas é questionável, assim como o sistema imposto pela Sereníssima República. Seria razoável afirmar que Machado propõe um exercício de interpretação crítica da realidade ao ironizar o funcionamento desregulado da república regida pelas aranhas.

O narrador de "A Sereníssima República" demonstra a importância das aranhas ao relacioná-las com cientistas que as haviam estudado: Plínio, Darwin e Büchner: "Tenho-os aqui, não todos, mas quase todos; tenho, entre eles, esta excelente monografia de Büchner, que com tanta subtileza estudou a vida psíquica dos animais". ${ }^{40}$ No seu estudo sobre os animais, Mind in Animals, Ludwig Büchner analisa as aranhas, sua capacidade como predadoras e sua sensibilidade: "[...] seus movimentos são rápidos, poderosos e ágeis, sua enorme sensibilidade, sua resistência, sua coragem durante o ataque, sua habilidade nas teias e sua tenacidade de vida são características maravilhosas". ${ }^{41}$ Torna-se claro que Machado de Assis era um conhecedor de Plínio, Darwin e Büchner, e que as aranhas em "A Sereníssima República" constituem uma representação de tais estudos com uma grande dose de sátira.

No tocante a religião, Machado novamente recorre à estatura para referir-se ao sentimento de inferioridade das aranhas. Assim como no capítulo da borboleta negra em

\footnotetext{
39 Traduz-se para: "Seria fácil provar que o Brasil é menos uma monarquia constitucional do que uma oligarquia absoluta." ASSIS, Machado de. Bons Dias! Org. John Gledson. Campinas: Editora da Unicamp, 2008. p. 103.

${ }^{40}$ ASSIS, Machado de. A Sereníssima República, cit., p. 243.

${ }^{41}$ Tradução minha para: "[...] Their movements are rapid, powerful and dexterous, their sensibility very great, their endurance, their courage on attack, their skill in the web, their tenacity of life, are wonderful." BÜCHNER, Ludwig. Mind in animals. Londres: Freethought Publishing Company, 1880. p. 313.
} 
MPBC, os animais menores sentem-se ameaçados pela presença do homem e atribuem a ele a sua criação: "A minha estatura, as vestes talares, o uso do mesmo idioma, fizeramlhes crer que era eu o deus das aranhas, e desde então adoravam-me". ${ }^{42}$ Trata-se de outra instância na qual o homem é o Deus, o criador. Machado faz então uma crítica severa à religião; afinal, cremos naquilo que não conhecemos, que é maior que nós mesmos: o criador; logo, para uma aranha, um homem pode ser o criador.

Além de incluir animais como personagens dentro de narrativas, ou de dedicar um capítulo inteiro a uma borboleta, Machado de Assis também constrói metáforas com a imagem de animais, visando acentuar determinadas características de certos personagens. Ao ler uma metáfora, o leitor formula uma imagem mental do sentido semântico da palavra aplicado ao contexto dos personagens. No caso de Machado de Assis, as metáforas com o uso de animais correspondem às características psicológicas das personagens. George Lakoff, em seu livro Metaphor and thought, explica com precisão o uso da metáfora como um processo mental:

Se metáforas são meramente expressões linguísticas, poderíamos concluir que as várias expressões da língua possuiriam suas metáforas correspondentes. Então, "temos uma rua sem saída" deveria corresponder a uma metáfora [...] Devemos notar que os teóricos contemporâneos que estudam o uso das metáforas normalmente referem-se ao termo "metáfora" para se referir ao mapeamento conceitual, e referem-se ao termo "expressão metafórica" para expressões individuais (como uma rua sem saída) que é sancionada por um mapa. Adotamos esta terminologia pela seguinte razão: Metáfora, como um fenômeno, envolve o mapeamento conceitual e as expressões linguísticas individuais. ${ }^{43}$

Podemos observar o uso da metáfora como uma estratégia narrativa de Machado no conto "Capítulo dos chapéus", no qual a personagem Mariana é comparada

\footnotetext{
${ }^{42}$ ASSIS, Machado de. A Sereníssima República, cit., p. 245.

43 Tradução minha para: "If metaphors were merely linguistic expressions, we would expect different linguistic expressions to be different metaphors. Thus, 'we have hit a dead-end street' would constitute one metaphor [...] It should be noted that contemporary metaphor theorists, commonly use the term 'metaphor' to refer to the conceptual mapping, and the term 'metaphorical expression' to refer to an individual expression (like dead-end street) that is sanctioned by a mapping. We have adopted this terminology for the following reason: Metaphor, as a phenomenon involves both conceptual mappings and individual linguistic expressions." LAKOFF, George. Metaphor and thought. Andrew Ortony (Ed.). Cambridge: Cambridge University Press, 1998. p. 209.
} 
a uma pomba e Sofia é comparada a um gavião. Observemos o momento em que Sofia convida Mariana para sair, e esta não tem outra escapatória senão aceitar (o trecho se inicia com a fala de Sofia):

- Vamos, um bocadinho só; eu também estou muito cansada...

Mariana teimou ainda um pouco; mas teimar contra Sofia - a pomba discutindo com o gavião - era realmente insensatez. Não teve remédio, foi. ${ }^{44}$

O mapeamento mental sugerido por Lakoff implica que o leitor do conto cria uma conexão entre Mariana e a rola, dada a natureza plácida desta personagem e o seu gosto pela paz do seu lar. Já o gavião é associado à amiga Sofia, em função de sua firmeza de ser, sua convicção e capacidade de manipulação: "Sofia tinha trinta anos, mais dous que Mariana. Era alta, forte, muito senhora de si". ${ }^{45}$ No mapeamento mental dessa metáfora, Sofia demonstra sua superioridade à Mariana já no primeiro contato entre as duas amigas. Sofia veste-se pomposamente e chama mais a atenção dos homens do que Mariana. Além da sua presença física imponente (como a do gavião), Sofia também domina Mariana com suas atitudes. A decisão de irem tirar um retrato, de irem ao dentista e à Câmara não são vontades de Mariana, mas sim de Sofia; no entanto, a mais fraca (Mariana) acata e segue a mais forte (Sofia). Quando finalmente Mariana está livre de sua amiga, quase ao final do conto, o narrador nos oferece novamente o uso da metáfora: "Mariana respirou. A rola estava livre do gavião". ${ }^{46}$

Seguindo esta mesma linha de raciocínio, a metáfora da pomba aparece em MPBC, no capítulo XCIII, quando Sabina tenta convencer Brás de que a filha de Damasceno, D. Eulália, é um bom partido para ele: "E dizia isto a bater-me na face com os dedos, meiga como uma pomba, e ao mesmo tempo intimativa e resoluta". ${ }^{47} \mathrm{~A}$ imagem de uma pomba é utilizada para demonstrar a ternura e a suavidade com que Sabina trata Brás.

\footnotetext{
${ }^{44}$ ASSIS, Machado de. Capítulo dos chapéus. Contos. São Paulo: Editora Cultrix, 1967. p. 125.

${ }^{45}$ Idem, p. 119.

${ }^{46}$ Idem, p. 127.

${ }^{47}$ ASSIS, Machado de. Memórias póstumas de Brás Cubas, cit., p. 282.
} 
Já em QB, no capítulo XXXIX, Rubião é comparado a um gavião, quando resolve demonstrar os seus afetos por Sofia: "Sofia é que não sabia o que fizesse. Trouxera ao colo um pombinho, manso e quieto, e sai-lhe um gavião - um gavião adunco e faminto". ${ }^{48} \mathrm{~A}$ imagem do gavião denota a agressividade de Rubião, tal como uma ave de rapina. A metáfora por si só já demonstra a situação em que Sofia se encontra e a mudança de atitude de Rubião, o qual começa a galantear Sofia.

Esses três exemplos do uso de metáforas servem apenas para demonstrar o poder do uso dessa figura de estilo associada à imagem de animais, representando personagens e situações dentro da narrativa. Essa técnica utilizada por Machado repetese com certa frequência em seus contos e romances, atestando a importância da metáfora na obra do autor.

A complexidade dos romances e dos contos de Machado de Assis analisados neste artigo apresentam elementos variados da ciência e da literatura universal também na representação animal. O cachorro em QB; o verme, o hipopótamo e a borboleta em MPBC; e a aranha no conto "A Sereníssima República" possuem funções narrativas específicas. As imagens desses animais correspondem a uma tradição literária e constituem-se em elementos discursivos importantes em suas respectivas narrativas.

Referências:

ASSIS, Machado de. A Sereníssima República. Obras Completas de Machado de Assis. Papéis Avulsos. v. 12. Org. Ary de Mesquita. São Paulo: W. M. Jackson, 1957. Bons Dias! Org. John Gledson. Campinas: Editora da Unicamp, 2008. Capítulo dos chapéus. Contos. São Paulo: Editora Cultrix, 1967. . Memórias póstumas de Brás Cubas. Obras Completas de Machado de Assis. v. 5. Org. Ary de Mesquita. São Paulo: W. M. Jackson, 1957.

${ }^{48}$ ASSIS. Machado de. Quincas Borba, cit., p. 95. 
Quincas Borba. Edição do texto e notas: Eugênio Vinci de Moraes. Prefácio: Willi Bolle. São Paulo: Editora Globo S.A., 2008.

BOSI, Alfredo. Brás Cubas em três versões: estudos machadianos. São Paulo: Companhia das Letras, 2006.

BÜCHNER, Ludwig. Mind in animals. Londres: Freethought Publishing Company, 1880 .

CIRLOT, Juan Eduardo. A dictionary of symbols [Un diccionário de símbolos actuales]. Jack Sage (trad). Nova Iorque: Dover, 2002.

FARIA, Marcos. Behemoth, Lilith e Anjos: três monstros judaicos em Jorge Luis Borges. Arquivo Maaravi: revista digital de estudos judaicos da UFMG, Belo Horizonte: v.3, n.5, out. 2009. Disponível em: <www.periodicos.letras.ufmg.br/index.php/maaravi>. Acesso em: 2 fev. 2012.

FERBER, Michael. A dictionary of literary symbols. Nova Iorque: Cambridge University Press, 2007.

LAKOFF, George. Metaphor and thought. Andrew Ortony (Ed.). Cambridge: Cambridge University Press, 1998.

PIZA, Daniel. Machado de Assis: um gênio brasileiro. São Paulo: Imprensa Oficial, 2008.

TRESIDDER, Jack. The complete dictionary of symbols. São Francisco: Chronicle Books, 2005.

Eduardo Viana da Silva é mestre em literatura luso-brasileira pela Brigham Young University (Utah, EUA) e atualmente está cursando um doutorado em literatura e uma especialização em linguística aplicada na Universidade da Califórnia em Santa Barbara. É contribuidor do wiki Português Língua Estrangeira - PLE e publicou recentemente uma resenha do livro Português Descomplicado no Portuguese Language Journal PLE. Sua tese de doutorado trata da representação de lendas medievais em Grande Sertão Veredas. E-mail: <eduardodasilva@umail.ucsb.edu>

Artigo: 22/02/2012

Aprovado: 18/05/2012 